\title{
Topical aldose reductase inhibitor for correcting corneal endothelial changes in diabetic patients
}

\author{
Nobuyuki Ohguro, Mamoru Matsuda, Yuichi Ohashi, Masakatsu Fukuda
}

\begin{abstract}
Background-Marked variations in cell size (polymegethism) and shape (pleomorphism) are characteristic of the corneal endothelium in diabetic patients and animals.

Method-Wide field specular microscopy was used to evaluate the clinical efficacy of treating the diabetic corneal endothelium with topical instillation of $0.5 \%$ aldose reductase inhibitor, CT-112.

Results-Morphological variations (polymegethism and pleomorphism) of the endothelium in eight eyes from eight patients receiving CT-112 resolved within 3 months after initiation of treatment. In contrast, no change in endothelial morphology was noted in five eyes from five patients who received placebo.

Conclusion-These observations suggest that aldose reductase may be involved in the aetiology of corneal endothelial variations in diabetic patients.
\end{abstract}

(Br f Ophthalmol 1995; 79: 1074-1077)

Previous specular microscopic studies have demonstrated a significantly higher coefficient of variation in cell size (polymegethism) and a marked decrease in the percentage of hexagonal cells (pleomorphism) in the corneal endothelium of diabetic patients ${ }^{12}$ and chemically induced diabetic animals. ${ }^{3-5}$ These morphological changes in other conditions have been associated with low functional reserve, ${ }^{16-9}$ and hence more vulnerability to a variety of insults. ${ }^{10}$

Aldose reductase (AR), the first enzyme of the polyol pathway, has been implicated in the pathogenesis of a number of diabetic complications. ${ }^{11}$ In view of the demonstration of AR in the corneal endothelium of humans ${ }^{12}$ and animals, ${ }^{1314}$ it is possible that $A R$ is also involved in the aetiology of the endothelial changes in the diabetic cornea. This concept is supported by the results of previous studies showing that several AR inhibitors (CT-112,

Accepted for publication

27 June 1995

Table 1 Clinical profile and endothelial morphology (mean (SEM))

\begin{tabular}{|c|c|c|c|}
\hline Clinical profile & $C T-112$ treated & Placebo treated & Non-diabetic \\
\hline $\begin{array}{l}\text { No of eyes } \\
\text { Age (years) } \\
\text { Duration of diabetes (years) } \\
\text { Retinopathy (NDR/SDR/PDR) } \\
\text { Endothelial morphology }\end{array}$ & $\begin{array}{l}8 \\
65 \cdot 1(8 \cdot 5) \\
16 \cdot 6(14 \cdot 4) \\
3 / 3 / 2\end{array}$ & $\begin{array}{l}5 \\
66 \cdot 2(7 \cdot 4) \\
13 \cdot 8(9 \cdot 6) \\
0 / 5 / 0\end{array}$ & $\begin{array}{l}20 \\
65 \cdot 7(5 \cdot 8) \\
- \\
-\end{array}$ \\
\hline $\begin{array}{l}\text { Endothelial morphology } \\
\text { Cell density (cells/mm²) } \\
\text { Coefficient of variation } \\
\text { Hexagonal cells }(\%)\end{array}$ & $\begin{array}{c}3059(91) \\
0.340(0.014)^{\star} \\
53.8(1.4) \dagger\end{array}$ & $\begin{array}{l}2982(34) \\
0.320(0.018)^{\star \star} \\
53.3(2.0) \ddagger\end{array}$ & $\begin{array}{c}2923(61) \\
0.284(0.007) \\
64.6(1.0)\end{array}$ \\
\hline
\end{tabular}

The severity of diabetic retinopathy was defined at the end of the study. NDR=no diabetic retinopathy; $S D R=$ simple (background) diabetic retinopathy; $P D R=$ proliferative diabetic retinopathy. ${ }^{\star}{ }^{\star \star}, t, \neq:$ significantly different from non-diabetic group

${ }^{\star} p=0.0001,{ }^{\star}{ }_{p}=0.028, t, \neq p$ is less than 0.001 .
AL-1576, and solbinil) are effective in preventing or reversing corneal endothelial changes in diabetic rats ${ }^{45}$ and galactosaemic dogs. ${ }^{15}$ Consequently, the present preliminary study was undertaken to determine the clinical efficacy of treating the diabetic corneal endothelium with topical AR inhibitor, CT-112. It has been shown that topically applied CT-112 can penetrate the cornea at sufficient concentrations to inhibit the activity of AR in the lens and can be taken up by the endothelial cells. ${ }^{16}$

\section{Materials and methods}

Thirteen patients with type II diabetes mellitus, ranging in age from 48 to 78 years (mean 66 years), were selected at random from a large group of diabetic patients seen at Osaka University Medical School, Japan. Twenty non-diabetic subjects of similar age served as a control group. We excluded patients who had trauma, ocular surgery, retinal photocoagulation, contact lens wear, or ocular disease. After a medical history was obtained, a complete routine eye examination was performed, and the subjects were excluded if any abnormal pathology that might affect the morphology of the corneal endothelium was noted. All of the 13 diabetic patients were found to have no diabetic retinopathy or simple (background) retinopathy at the pretreatment examination. During the observation period, however, neovascularisations of the retinal vessels elsewhere (proliferative diabetic retinopathy) appeared in two of the CT-112 treated patients. In these patients, retinal photocoagulation was performed after the entire study was completed.

After obtaining informed consent, the 13 diabetic patients were assigned by random number selection to have eyedrops of either an AR inhibitor (CT-112) or a placebo. While $0.5 \%$ CT-112 (5-[3-ethoxy-4-pentyloxyphenyl]-2,4-thiozolidinedione; Senju Pharmaceutical Co Ltd, Osaka, Japan) dissolved in an acetate buffer solution was applied to the both corneas in the CT-112 treated group (eight patients) four times a day for 6 months, the placebo treated group (five patients) received a drop of the vehicle alone in the same manner. On each of the follow up visits during the study period, the patient's symptoms were noted and signs of ocular side effects were evaluated by routine clinical tests. These clinical evaluations were performed by two of us (MF and YO) who were aware of which patients received CT-112 or placebo.

The endothelium of the central cornea was photographed with a wide field specular microscope. Approximately 10 to 15 photographs were taken of each cornea. In both the CT-112 

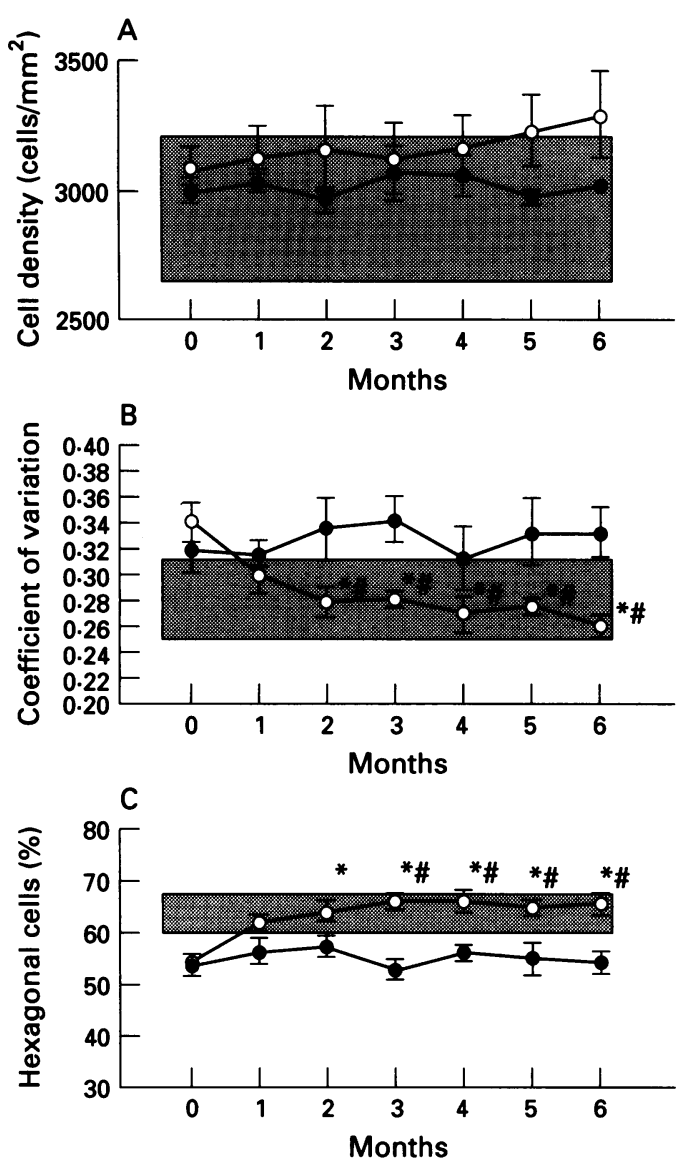

Figure 1 (A) Changes in cell density of the corneal endothelium. (B) Changes in coefficient of variation in cell size of the corneal endothelium. (C) Changes in percentage of hexagonal cells of the corneal endothelium. (Versus pretreatment (paired t test), ${ }^{\star} p<0.01 ; C T-112$ versus placebo (unpaired $t$ test), ${ }_{p}<0 \cdot 01$. (O) Diabetics $+[C T-112]$, mean $(S E)(n=8) ;(O)$ diabetics + placebo, mean (SE) $(n=5)$; (N) non-diabetics, mean (SD) $(n=20)$.

and placebo treated diabetic patients, endothelial photographs were obtained monthly for 6 months after the initiation of the treatment. The endothelial morphology was measured only once in the control group. One eye per patient was randomly selected and used for the study. Three photographs with good resolution were chosen for each eye at each time point. In each photograph, a total of 100 adjacent cells

Table 2 Percentage changes of the corneal endothelial morphology (compared with the pre-treatment value)

\begin{tabular}{|c|c|c|c|c|}
\hline Time (months) & $C T-112$ treated & Placebo treated & $t_{0}$ & $p_{0}$ \\
\hline \multicolumn{5}{|l|}{ Cell density: } \\
\hline 1 & $1.7(25)$ & $1 \cdot 1(0.7)$ & 0.2147 & $0.8300 \mathrm{~ns}$ \\
\hline 2 & $2 \cdot 8(2 \cdot 0)$ & $-1.0(1.8)$ & $1 \cdot 3450$ & $0.1786 \mathrm{~ns}$ \\
\hline 3 & $1 \cdot 1(1.9)$ & $4.0(3.6)$ & -1.0274 & $0.3043 \mathrm{~ns}$ \\
\hline 4 & $2.9(2 \cdot 7)$ & $2.0(3.8)$ & 0.3133 & $0.7541 \mathrm{~ns}$ \\
\hline 5 & $5 \cdot 1(1.7)$ & $-0.4(0.9)$ & 1.9575 & $0.0503 \mathrm{~ns}$ \\
\hline \multirow{2}{*}{\multicolumn{5}{|c|}{ Coefficient of variation: }} \\
\hline & & & & \\
\hline 1 & $-13.3(2 \cdot 1)$ & $-3 \cdot 0(3 \cdot 2)$ & $-2 \cdot 3190$ & $0.0204 \mathrm{~ns}$ \\
\hline 2 & $-19.0(2.9)$ & $3.7(4 \cdot 8)$ & $-5 \cdot 1462$ & $0.0000^{\star}$ \\
\hline 3 & $-18 \cdot 1(4 \cdot 0)$ & $5.9(4.3)$ & -5.4314 & $0.0000^{\star}$ \\
\hline 4 & $-21.8(2 \cdot 2)$ & $-3.5(5.9)$ & $-4 \cdot 1371$ & $0.0000^{\star}$ \\
\hline 5 & $-19.2(6.3)$ & $3 \cdot 4(7 \cdot 2)$ & $-5 \cdot 1215$ & $0.0000^{\star}$ \\
\hline 6 & $-24.4(2.0)$ & $3.5(3.9)$ & $-6 \cdot 3048$ & $0.0000^{\star}$ \\
\hline \multicolumn{5}{|c|}{ Percentage of hexagonal cells: } \\
\hline 1 & $13 \cdot 6(4 \cdot 1)$ & $5 \cdot 3(2 \cdot 0)$ & $1 \cdot 6986$ & $0.0894 \mathrm{~ns}$ \\
\hline 2 & $17.8(3.9)$ & $7 \cdot 0(8 \cdot 1)$ & $2 \cdot 2045$ & $0.0275 \mathrm{~ns}$ \\
\hline 3 & $21 \cdot 6(3.2)$ & $-1 \cdot 7(4 \cdot 2)$ & $4 \cdot 7715$ & $0.0000^{\star}$ \\
\hline 4 & $21.9(5.0)$ & $4 \cdot 2(5 \cdot 7)$ & $3 \cdot 6071$ & $0.0003^{\star}$ \\
\hline 5 & $19 \cdot 4(4 \cdot 6)$ & $2 \cdot 1(2 \cdot 5)$ & 3.5259 & $0.0004^{\star}$ \\
\hline 6 & $20.9(1.4)$ & $1 \cdot 1(6 \cdot 1)$ & 4.0584 & $0.0000^{\star}$ \\
\hline
\end{tabular}

Mean $(\mathrm{SE}){ }^{\star} \mathrm{p}<0.01 ; 0.0000$ means that $\mathrm{p}$ is less than 0.0001 . were analysed with a computerised digitiser, as previously described. ${ }^{117}$ Morphological data for three photographs were averaged. Endothelial photography and morphological evaluation were performed by independent masked examiners (MM and NO) who were unaware of which eyedrop was used for any eye until the entire study was completed.

Endothelial cell density (cells $/ \mathrm{mm}^{2}$ ) was calculated by dividing $10^{6}$ by the mean cell size. The coefficient variation in cell size (the standard deviation of the cell size expressed as a ratio to the mean cell size) was used as a quantitative measurement of cell size variability (polymegethism). Cell shape was defined by the number of apices of each cell. The percentage of hexagonal cells was used to describe cell shape variability (pleomorphism).

Analysis of variance and unpaired $t$ test were used to analyse differences among the non-diabetic, CT-112 treated, and untreated diabetic groups for patient age, duration of diabetes, and baseline endothelial morphology (Table 1) $(\mathrm{p}<0.05)$. A paired $t$ test was used to compare the changes within the CT-112 treated and untreated diabetic groups (Fig 1). At each time point, an unpaired $t$ test was used to analyse differences between the percentage changes in the CT-112 treated group and those in the untreated group (Table 2). A p value of less than 0.01 was considered significant in this part of the study.

\section{Results}

There were no significant differences in age, duration of diabetes, and the severity of diabetic retinopathy between the CT-112 and placebo treated diabetic patients (Table 1). These groups were also comparable in terms of baseline endothelial status, including cell density, coefficient of variation in cell size, and percentage of hexagonal cells. When compared with the age matched controls, however, the endothelium of each of the diabetic groups showed no difference in cell density but demonstrated a significantly higher coefficient of variation in cell size and a marked decreased in the percentage of hexagonal cells.

During the 6 month study period, the endothelial cell density remained unchanged from the baseline values in both the CT-112 and placebo treated diabetic groups (Fig 1A). In the CT-112 treated group, the coefficient of variation decreased significantly (Fig 1B; $\mathrm{p}<0.01$ ) and the percentage of hexagonal cells increased markedly (Fig $1 \mathrm{C} ; \mathrm{p}<0.01$ ) from the baseline values 2 months after the initiation of the treatment. Both measurements returned gradually to normal within 3 months after treatment and stayed relatively constant thereafter. In contrast, no change in the coefficient of variation and the percentage of hexagonal cells was noted in the placebo treated diabetic group. Table 2 showed percentage changes in endothelial morphology at each time point in both the CT-112 and placebo treated diabetic groups. Three months after treatment, significant recovery in polymegethism and pleomorphism was observed in the CT-112 treated 


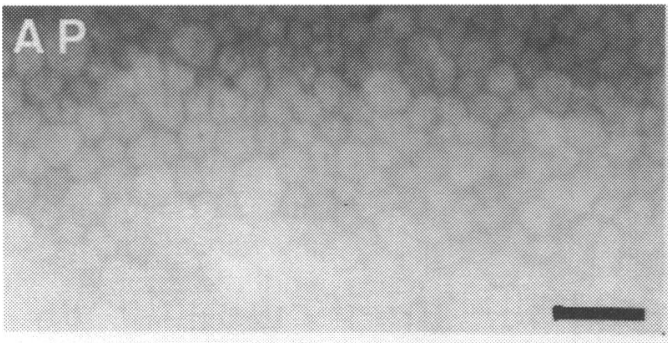

A A
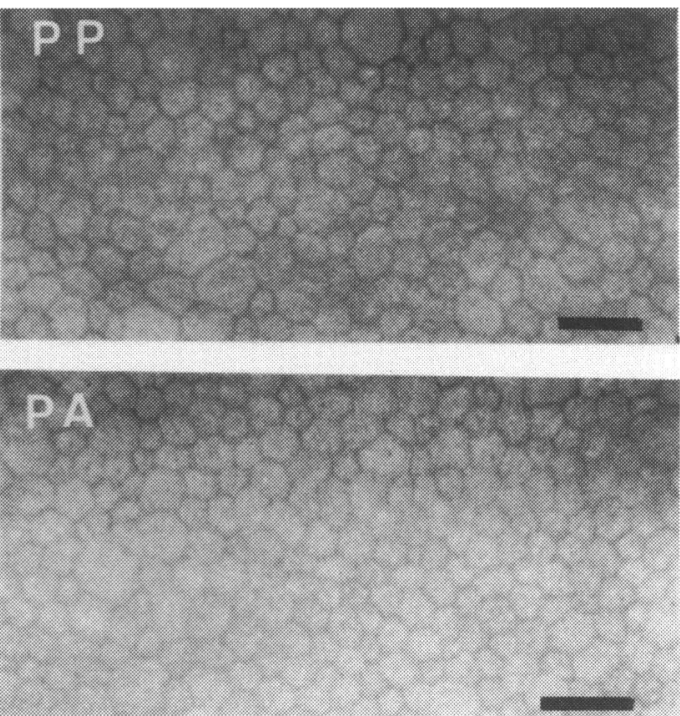

Figure 2 Specular microscope photographs of diabetic corneal endothelia before and after treatment with an aldose reductase inhibitor (ARI) or a placebo. Bar=50 $\mathrm{mm}$. (AP) ARI treated corneal endothelia (pretreatment) (cell density $3187 \mathrm{cells} / \mathrm{mm}^{2}$, coefficient of variation 0.425 , hexagonal cells $51 \%$ ). (AA) ARI treated corneal endothelia (after treatment) (cell density $3014 \mathrm{cells} / \mathrm{mm}^{2}$, coefficient of variation 0.324 hexagonal cells $60 \%$ ). (PP) Placebo treated corneal endothelia (pretreatment) (cell density 2846 cells $/ \mathrm{mm}^{2}$, coefficient of variation 0.456 hexagonal cells $42 \%$ ). (PA) Placebo treated corneal endothelia (after treatment) (cell density $2935 \mathrm{cells} / \mathrm{mm}^{2}$, coefficient of variation 0.424 hexagonal cells $49 \%$ ).

group when compared with the placebo treated group.

No intergroup difference, however, was found in cell density at any time point. Figure 2 demonstrates the typical appearance of the endothelial cells treated with CT-112 or placebo.

There were no CT-112 related ocular side effects involving visual acuity, anterior segment, intraocular pressure, and fundus appearance, although some patients noted occasionally mild irritation upon instillation.

\section{Discussion}

The results of this study demonstrate that, consistent with previous reports, ${ }^{12}$ the corneal endothelium in diabetic patients had marked polymegethism and pleomorphism, which can be substantially reversed with a topical $A R$ inhibitor, CT-112. Similarly, topical application of several AR inhibitors has been shown to be effective in preventing or reversing the corneal endothelial changes in diabetic rats ${ }^{3}$ and galactosaemic dogs. ${ }^{5}$ The regeneration of the corneal endothelium was also found to be delayed in galactosaemic rats and was corrected by administration of AR inhibitors. ${ }^{18}$ Furthermore, the presence of AR has been demonstrated immunohistochemically in the corneal endothelium of humans ${ }^{12}$ and animals. ${ }^{13} 14$ These observations suggest that AR may be involved in the diabetes induced abnormalities of the corneal endothelium, as it is in the diabetic complications of other tissues. ${ }^{11}$

The exact mechanism by which $\mathrm{AR}$ induces the corneal endothelial morphological changes remains unclear, but it may be related to intercellular accumulation of polyols. As in the sugar cataract formation, ${ }^{11}$ the polyols may accumulate to unusually high levels, causing an osmotic imbalance that may lead to cell swelling and disruption. Another explanation is that, as in the diabetic nerve, ${ }^{11}$ the level of the polyol accumulation is not sufficient to cause the osmotic effect, while it may cause a depletion of intracellular myoinositol and a subsequent decrease in the membrane bound $\mathrm{Na} / \mathrm{K}$ dependent ATPase, resulting in cell swelling and death.

Several studies have indicated that even with normal cell density, polymegethism and pleomorphism reflect a low functional reserve and instability of endothelial cells. ${ }^{6-9}$ This may partially explain a higher incidence of persistent corneal oedema postoperatively in diabetic patients. ${ }^{10}$ In this study, topical CT-112 was found to be effective in reversing the diabetic endothelial changes to the normal range within 3 months after treatment. In order to decrease the incidence or degree of postoperative corneal oedema, therefore, it may be beneficial to treat the diabetic endothelium with topical AR inhibitors for several months before intraocular surgeries are indicated.

Our previous clinical trials of topical CT112 have been successful in patients with a variety of diabetic corneal epithelial abnormalities. ${ }^{1920}$ The present preliminary clinical study demonstrates that topical CT-112 is also effective in correcting the endothelial morphological changes of the diabetic corneas. In these studies, the only side effect we observed was transient, mild irritation upon instillation in some patients. Therefore, CT-112 does not appear to be toxic to the eye when applied topically in low, controlled doses. To explore the questions of safety, risks, and benefits, especially on a long term basis, we are currently conducting a randomised, controlled clinical study of the effects of topical CT-112 on the epithelium and endothelium of the diabetic cornea.

This study was supported in part by a research grant from the Osaka Eye Bank, Osaka, Japan.

1 Shultz RO, Matsuda M, Yee RW, Ederhauser HF, Schultz KJ. Corneal endothelial changes in diabetes mellitus. Am f Ophthalmol 1984; 98: 401-10. 
2 Matsuda $M$, Ohguro $N$, Ishimoto I, Fukuda $M$ Relationship of corneal endothelial morphology to diabetic retinopathy, duration of diabetes and glycemic control. Ipn f Ophthalmol 1990; 34: 53-6.

3 Yee RW, Matsuda M, Kern TS, Engerman RL, Ederhause HF. Corneal endothelial changes in diabetic dogs. Cur Eye Res 1985; 4: 759-66.

4 Matsuda $M$, Awata $T$, Ohashi $Y$, Inaba $M$, Fukuda $M$ Manabe $\mathbf{R}$. The effect of aldose reductase inhibitor on the corneal endothelial morphology in diabetic rats. Curr Eye Res 1987; 6: 391-7.

5 Meyer LA, Ubels JL, Ederhauser HF. Corneal endothelia morphology in the rat: effects of aging, diabetes, and topical aldose reductase inhibito

6 Rao GN, Shaw EL, Arthur EJ, Aquavella JF. Endothelia cell morphology and corneal deturgescence. Ann Ophthalmol 1978; 11: 885-99.

7 Bourne WM, Brubaker RF, O'Fallonn WM. Use of air to decrease endothelial cell loss during intraocular lens implantation. Arch Ophthalmol 1979; 97: 1473-5.

8 Rao GN, Aquarella JV, Goldberg SH, Berk SL Pseudophakic bullous keratopathy: relationships to preopPseudophakic bullous keratopathy: relationships to preop-
erative endothelial status. Ophthalmology 1984; 91: erative $1135-40$.

9 O'Neal MR, Polse KA. Decreased endothelial pump function with aging. Invest Ophthalmol Vis Sci 1986; 27: 457-63.

10 Foulks GN, Thoft RA, Perry HD, Tolentino FI. Factors related to corneal epithelial complications after closed vitrectomy. Arch Ophthalmol 1979; 97: 1076-8.

11 Dvornik D, Porte D. Aldose reductase inhibition: an approach to prevention of diabetic complications. New York:
Biomedical Information Corporation, 1987.

12 Akagi Y, Yajima Y, Kador PF, Kuwabara T, Kinoshita JH. Localization of aldose reductase in the human eye. Diabetes 1984; 33: 562-6.

13 Ludvigson M, Sorenson R. Immunohistochemical localization of aldose reductase. II. Rat eye and kidney. Diabetes 1980; 29: 450-9.

14 Kern TS, Engerman RL. Distribution of aldose reductase in ocular tissues. Exp Eye Res 1981; 33: 175-82.

15 Datiles MB, Kador PF, Kashima K, Kinoshita JH, Sinha A. The effects of Sorbinil, an aldose reductase inhibitor, on the corneal endothelium in galactosemic dogs. Invest Ophthalmol Vis Sci 1990; 31: 2201-4.

16 Ohashi Y, Awata T, Sogo S, Ohira M, Matsuda M, Fukuda M, Manabe R. Intraocular penetration of CT-112, an aldose reductase inhibitor, following topical instillation. $\mathcal{F}$ Ocul Pharmacol 1989; 5: 325-8.

17 Matsuda M, Suda T, Manabe R. Quantitative analysis of endothelial mosaic pattern changes in anterior keratoconus. Am f Ophthalmol 1984; 98: 43-9.

18 Akagi Y, Takahashi Y, Ikebe H, Kador PF, Kinoshita JH. Repair of comeal endothelium in galactosemic rats. Polyol pathway and its role in diabetic complications. Amsterdam: pathway and its role in diabetic com

19 Manabe $R$, Matsuda M, Ohashi Y. Diabetic keratopathy and the effects of aldose reductase inhibitor. In: The cornea: transaction of the world congress on the cornea III. New York: Raven Press, 1988: 131-4.

20 Ohashi Y, Matsuda M, Hosotani H, Tano, Y, Ishimoto I, Fukuda M, Manabe $R$. Aldose reductase inhibitor (CT-112) eyedrops for diabetic corneal epitheliopathy. Am f Ophthalmol 1988; 105: 233-8. 